\title{
Research on Career Planning of Public Institutions Employees
}

\author{
Na Song ${ }^{1}$ \\ ${ }^{1}$ Tianjin University of Finance and Economics, Tianjin, China, 300000
}

KEYWORDS: Career Planning, Public Institutions, Employees

\begin{abstract}
Staff career planning and management is an important part of modern human resources management, but also the management of public institutions and urgent attention to the field of development. Career planning and management mainly relates to self-management and organizational management aspects. This paper analyzes the institution of traditional management problems and to carry out PSU staff career planning carried out related research.
\end{abstract}

\section{Introduction}

Faced with increasingly fierce market competition, a public institution would like to get long-term, stable and sustainable development, and an invincible position in the competition, it is necessary to develop long-term strategic development plan based on the actual situation and their own characteristics in stages. At the same time, institutions should be in terms of human, material and financial resources and systems to provide effective protection and effective organization to achieve strategic objectives of each stage. Similarly, as the institution's staff, in order to better enhance and develop their own, gain recognition and respect for the community and others, to achieve self-worth, you have to plan their careers and institutions should also help their professional staff effective career planning and effective management of this system.

\section{The Overview of Career Planning}

Career, by definition, is a person's life experience in one or more of the entire profession. Specifically, it refers to a person by virtue of their work from the beginning to obtain legal income no longer rely on labor income made up the life course. This course may be intermittent, or continuous, which contains all of one's work, career, changing jobs and external attitude, change internal experience.

Career planning, refers to individual employees and work units combined were analyzed in individuals with subjective and objective conditions, basic research on the comprehensive consideration and weigh individual strengths, interests, hobbies and deficiencies and other aspects, and in accordance with their professional orientation, to determine the best career goals, and make a reasonable arrangement for the dynamic process of achieving this goal. Career management is an enterprise to provide help for the enterprise are engaged in the process of career employees of certain types of behavior, it is the business plan for its employees to achieve career goals carried out, directing, and controlling management activities aimed at the workers personal needs and the needs of enterprises unify be utilized, can mobilize the enthusiasm of employees, increase their sense of belonging. It should be noted that career management is not just for business, for institutions is also applicable. 
Career planning and management plays an increasingly important role in public institutions. Successful career planning and management institutions not only meet the demand for talent, but also to meet the requirements of employee self-development, so as to realize employee growth and development units in unison, a win-win situation well in hand.

\section{The Problems of Traditional Public Sector Employees Career Development}

For a long time, institutions and personnel management is not suited to their system, mostly referring to government agencies approach and a few companies with reference to the provisions do not meet the actual situation of institution. Since the long-term effect of "Official Standard" thinking, people tend to get used to the administrative level to measure the success of their own and others' business. In real life, work, never enough of senior positions so that each person's promotion to become a reality. Generally, to reach the pinnacle of career employees work performance will be reduced when workers hampered due to personal development and achieve career peak, the mood becomes abnormal, career frustration will lead to poor staff attitude, poor work performance. Therefore, when a person's job title and job content due to a lack of opportunity for advancement within the organization remain unchanged (commonly known as the "ceiling" phenomenon) occurs stagnation, not only for individual career development, and the organization's overall performance will have a serious negative impact.

In the traditional management mode, although the PSU staff is divided into administrative, professional and technical workers and service categories, but mainly divided based on the identity of the condition due to the lack of administrative staff and workers and service development ladder, many administrative, logistical staff also trying to comment on the senior title, in some places even a very strange title series, the impact of professional titles of academic seriousness. In practice, there are also shortcomings in title evaluation. First, seniority is serious, they tend to make whizzes, strong ability to work, bear the main tasks of the middle-aged, young people are affected in the promotion of the titles, and dampen their enthusiasm for work; Second, job classification and quantitative criteria does not specification, some people in order to achieve scientific research papers or state standards and fraud, corrupt people's minds, corrupt social values, academic corruption has become a very serious social problems; Third, professional and technical titles of Employment and the actual working out of line, resulting in changes in titles and job responsibilities, job performance irrelevant phenomenon; Fourth incentives Professional titles job classification system can not be solved after many titles in constant promotion, the ability to work has not been accompanied by growth in the commentary on the title later, no longer writing papers, and does not assume the title of the corresponding contractual duties, be confused with ordinary workers. The existence of these problems, make the institutions employing mechanism is not active, workers job is basically for life, affecting staff motivation, creative play, affecting the unit dynamic play, restricted the healthy development of the institutions of the urgent need to post setting management reform laws establish a set of characteristics of public institutions management practices and personnel systems.

\section{Career Planning of Public Institution Staff}

Institutions on staff career planning so that employees personal growth and development in a planned, systematic and dynamic, so that workers can continue to get more education and training opportunities, continue to stage career to a higher level. Career anchor is a famous American expert career guidance, mercy MIT professor proposed, he believes, in fact, career development is a 
continuous process of exploration, everyone according to their talent, ability, motivation, needs, attitudes and values and other factors gradually formed its own relatively clear self-concept and career-related. As more and more understanding of their own, will form a dominant "career anchor" occupational center anchor is that people actually choose and develop their career surrounded. Professor Schein career anchors will be divided into five kinds of technical, managerial, creative, safe and independent type, etc., specific to the institutions, mainly technical and managerial career anchor career anchor. Technical career anchor is characterized by a particular technology or emphasize practical skills of operations, general management refused to work, the pursuit of growth and continuous improvement of professional skills in the technical capacity of the region; managerial career anchor is characterized by the pursuit of a general commitment management, with a strong motivation promotion, excellent management, the organization can have a greater dependence.

Institution staff in the development of personal career planning, to analyze the environmental conditions, the characteristics of the development of changes in the environment, their relationship with the environment, in their own environment, the status of the environment on their own requests and the environment to their advantage and negative aspects, etc., according to their different personalities, pursuit, needs and values, by location, and determine their own career anchor. For certain professional work to pursue a specific career needs and specific values, do not want to choose a career in general management with nature, and tend to choose to ensure that workers continue to receive career development in a specific career field capacity, should Select technical career anchor; willing to engage in a comprehensive management work, there is a want to be a strong incentive to managers, having analytical skills, interpersonal skills and emotional competence combined skills, good influence, supervision, direction and control of sector members and effectively achieve departmental objectives, professional experience has been gained to convince themselves that have the ability to enhance the managerial positions, but also very confident to get the opportunity to assume greater responsibility for management positions in pursuit of higher management positions as a career workers ultimate goal should be selected managerial career anchor.

Post setting management offers two career courses for PSU employees. One is the management career ladder along this road can be accessible senior management positions; one is professional and technical career ladder along this road can be accessible senior professional and technical positions. Institutions to deal with the personnel department employees have long-term career planning and systematic plan, based on the job settings management, help employees develop career planning. Let employees be more accurate self-evaluation, the employee's own characteristics, design appropriate career development and objectives; the analysis of the staff analysis and unit positions, select the appropriate professional positions for workers to help staff determine the career path and draw career roadmap; depending on the situation of workers, the development of different career strategy. The early stage of his career, workers like constantly self-exploration, looking for their own career development; the mid-stage of his career, family, job security and social status have more consideration, eager to get promoted to flag professional achievement; late stage of his career, you can create some opportunities or provide some conditions to develop wholesome activities to create a atmosphere full of human tissue.

Career planning and management of public institutions and the mutual responsibility of individual employees, units and employees must work together to participate in the process of career planning and manage. From the perspective of institutions, career planning and management for employees' features tailored, with strong uniqueness and exclusivity. Effective implementation 
of career planning and management should do the following tasks: to carry out research work through various means, the unit of analysis needs and personal needs and find the combination of the two points. HR institutions can be classified, stratified, method and other methods to carry out targeted capacity of individual employees and the inherent potential of a comprehensive assessment, and the ability to accurately evaluate potential employees, and according to the various units needs help employees develop practical career planning.

Be creative and set up a variety of career path for the growth of staff. Career Pathways refers way to change careers staff to achieve career goals and set up required, it is to help people manage the growing program. Career path for the career development of the employees pointed out the direction, so that each employee can develop through their own efforts and transform their work units. For example, institutions, researchers can learn through training, competition, etc. into management positions and served as a certain position. So that one can mobilize their intrinsic motivation, better achieve organizational goals; on the other hand, can inspire employees motivated and fully tap the potential of employees' work. Through technical exchanges, internal training, external training, corporate culture and the ideological and political education to learn other ways improve the operational capacity and the overall quality of staff, especially young employees.

Institutions should strive to build a two-way flow of talent mechanism, to realize rational flow of talent. Have management skills of researchers, can be adjusted to the appropriate management positions; there are technical advantages of management, can be adjusted to the appropriate research post work. This will continue to improve the overall quality of staff, provide training opportunities for staff to achieve career goals.

Provide equal opportunities for career development and the establishment of supporting systems for employees. Widespread implementation of competition for employment system, build a stage to display their talent for every employee, so that one be able to attract and retain qualified personnel, the staff of the organization to enhance the sense of identity; the other hand, to the greatest degree stimulate their enthusiasm for work, provide an endless driving force for developing it.

\section{Conclusion}

All in all, an effective career planning and management needs of both institutions and employees to work together. I believe that the institutions of human resources practitioners should be adhering to the "external balance situation, the amount of own strength," the guiding principle, through the "winter plan, spring planting, summer work, fall harvest," the management process, and the efforts of its own staff active cooperation, to help employees make career planning and management work together to create a "train and retain qualified personnel, a win-win" a good situation.

\section{REFERENCE:}

[1] Tan Yongsheng, Li Miao, Fu Qingfeng. Executive Career Management [M]. Beijing: China Development Press, 2008.

[2] Chenxi Yan Qiu Zhu military. Successful implementation of the Career Planning and Management [J]. Weifang University, 2011 (2): 112-113.

[3] Feng Feifei, once green, Feng Jianwei. SOEs New College Students Career Planning and Management Research [J]. Hebei enterprises, 2011 (3): 63-64.

[4] Gauci. Career Planning basic steps [J]. Northwest Vocational Education, 2006 (11): 34-36.

[5] Yang Yuxin. Investigate individual career planning and management level employees of the SMEs in research [J]. Science and Technology Information, 2011 (07): 101-102. 